\title{
A pesquisa em sala de aula como prática pedagógica emergente para a qualidade do ensino superior
}

\author{
Maria Janine Dalpiaz Reschke ${ }^{1}$ \\ Juliana Bittencourt Garcia ${ }^{2}$
}

\section{RESUMO}

Este estudo objetivou compreender como docentes, que se envolvem no projeto "Mostra de Pesquisa em Sala de Aula", em uma universidade comunitária no sul do Brasil, buscam estratégias para utilizar a investigação como princípio educativo e inovador em sala de aula. Para sua realização foi feito um levantamento das experiências apresentadas na Mostra de Pesquisa de 2010 até 2017. Para tal, foram analisados os textos apresentados com a descrição da experiência, observando o número de professores envolvidos, a natureza dos trabalhos e a participação dos estudantes. A motivação dos professores envolvidos na Mostra também foi objeto de interesse. Entre eles há os que realizam investigações de forma sistemática e contínua, pertencentes a áreas acadêmicas distintas, com reconhecida competência docente. Foram realizadas entrevistas semi estruturadas com quinze professores, através de contato on line. A análise dos dados indicam que há fatores comuns que impactam as experiências, envolvendo a qualificação do professor, o compromisso social da universidade, o ensino relacionado com cotidiano, a capacidade de aprender a ensinar na prática social. Um destaque especial revela que os saberes da pesquisa estão presentes nas

\footnotetext{
1 Doutora em Educação. Professora da FACCAT - Faculdades Integradas de Taquara, Taquara, RS, Brasil. https://orcid.org/0000-0002-3456-749X. mjanine@terra.com.br

${ }^{2}$ Doutoranda do Programa de pós-graduação em Educação da UFPel - Universidade Federal de Pelotas, Pelotas, RS, Brasil. https://orcid.org/0000-0002-6467-5264.jbittencourtgarcia@ gmail.com

Este estudo teve o apoio da estudante de Pedagogia Kenia Silveira Marques da Universidade Luterana do Brasil ULBRA. Brasil. keniadasilveiramarques@gmail.com
} 
representações dos docentes quando manifestam sua compreensão da qualidade no ensino de graduação, encaminhando a perspectiva da indissociabilidade como referente da educação superior.

Palavras-chave: Docentes do ensino superior; Professores pesquisadores; Relação ensino e pesquisa; Docência e pesquisa.

Classroom search as emerging pedagogical practice for the quality in higher education

\begin{abstract}
This paper aims to understand how teachers than are involved in the project "Classroom Research Show", seek strategies to use research as an educational and innovative principle in the classroom. We conducted a survey of the Research Shows from 2010 to 2017. In this survey we could observe the number of teachers, assignments and students than participated. We also checked the reasons that led teachers to join the project or not. We map out some professionals than conduct research systematically, belonging to different academic areas and with recognized teaching competence. We conducted semi-structured interviews and online scripts with fifteen teachers. Our artificers seem to indicate that characteristics such as: teacher qualification, university social commitment, teaching related to daily life, learning to teach in the collective and research knowledge are present in their representations of quality understanding in undergraduate education.
\end{abstract}

Keywords: Higher Education Teachers; Research Professors; Teaching and research relationship; Teaching and research.

$$
* * *
$$

Se te mandam quebrar uma pedra ou fazer um móvel, a inteligência vai te angustiar na procura do meio mais certo, mais eficiente e mais perfeito de quebrar ou de fazer. Mas a insaciedade que te faz artista vai te atirar numa procura muito mais afetiva, digna e criadora: saber o que é uma cadeira, que proveito os outros tirarão da pedra que você vai quebrar. Sem isso você será escravo. 


\section{Introdução}

A universidade vem enfrentando desafios contemporâneos muito significativos, tendo em vista as mudanças culturais e científicas que incidem sobre suas práticas de ensinar e aprender. Historicamente, a universidade se constituiu como um referente do conhecimento acumulado e assumiu a responsabilidade de transmitir esse patrimônio cultural de uma geração à outra. O paradigma da ciência positivista repercutiu no papel social da educação escolarizada e na configuração da docência e da discência. Para tal perspectiva, o conhecimento válido seria somente o considerado pelo método científico e, com suas verdades, deveria ser veiculado para as novas gerações. As certezas eram valorizadas enquanto a duvida penalizada no espaço da prática pedagógica. Exigia-se um professor erudito, com intensa capacidade de conhecimento acumulado e um estudante com significativo poder de memorização.

Nas últimas décadas do século $\mathrm{XX}$, porém, esse paradigma foi mostrando uma incapacidade de enfrentamento dos problemas reais que exigiam a condição de múltiplas respostas. A ordem e a certeza foram dando lugar à valorização das perguntas e da capacidade de explorar novas alternativas de conhecimento. Mostra-se frágil um ensino prescritivo e a capacidade investigativa foi assumindo um valor nos processos de ensinar e aprender.

Não por acaso, o discurso da indissociabilidade do ensino pesquisa extensão se constituiu, no Brasil, como fundante da descrição da qualidade universitária, na Constituição de 1988.

A partir daí, e com o significativo empenho na formação pós-graduada de professores, a condição da pesquisa passou a ter relevância especial no cenário acadêmico. Atualmente as estatísticas informa que mais de $80 \%$ da pesquisa no Brasil, é realizada nas Universidades, com especial destaque às de natureza pública. 
Se esta conquista foi mudando o cenário acadêmico na produção do conhecimento, ficou cada vez mais evidente que os processos de ensinar e aprender teriam de sofrer significativas mudanças, assumindo os pressupostos da pesquisa na prática da aprendizagem.

Para tal, as mudanças nas tecnologias de informação muito contribuíram para evidenciar a emergência de um novo paradigma de ensino. O monopólio da informação que as instituições escolarizadas tiveram até esse período, foi quebrado pela possibilidade de a ela ter acesso pelos meios digitais. Nesse sentido, a docência tradicional foi fortemente atingida, exigindo dos docentes e também dos estudantes, novas perspectivas de ensinar e aprender. A duvida, tão penalizada pelo paradigma da pedagogia positivista, passou a ser valorizada, como elemento fundante de uma formação criativa. E a presença dos princípios da pesquisa no ensino se constituiu num especial desafio para os protagonistas da cena acadêmica.

Nesse sentido, iniciativas como a Mostra de Pesquisa em sala de aula evidenciam a necessidade de estimular as experiências nessa direção e compreender os saberes docentes e discentes que estão em pauta nesse cenário.

O objetivo deste estudo foi pesquisar este cenário de experiências para compreender os processos vividos por professores e estudantes que intencionam usar a pesquisa como processo formador na aula universitária.

O cenário principal é a sala de aula e, é a partir dela e nela, que procuramos nos apropriar da importância de pensar a docência universitária e os desdobramentos para a formação de professores.

Para tanto, foi necessário refletir sobre o entendimento do que é pesquisar. Ressaltamos que o ato de pesquisar está na base do ser humano; já desde os primeiros anos de vida somos pesquisadores e desde cedo questionamos e investigamos. A criança quer conhecer, desde a tenra idade, o mundo que a cerca, quais as origens das coisas. Quem de nós não tem na lembrança esses questionamentos? Os nossos filhos e filhas, sobrinhos e amigos podendo ficar dias ao lado dos adultos perguntando: mas,... Por quê? 
Perece que, quanto mais havia o gosto pelas respostas, mais curiosidade produzia, deixando os adultos perplexos com os questionamentos. As indagações feitas pelas crianças são sobre as coisas naturais e sociais e sobre si mesmas, que mais tarde, como sujeitos adultos e como pesquisadores potencializarão, desde que estimulados para tal.

Partimos, pois, do pressuposto que a necessidade básica para a pesquisa é a vontade de questionar, de buscar respostas, informações. O pesquisador pergunta de maneira sistematizada, com o apoio de teorias, métodos e técnicas, com a intenção de compreender melhor o mundo em que vive.

Buscando o entendimento do que significa pesquisa no dicionário Aurélio (2010, p.1320) encontramos: "indagação ou busca minuciosa para averiguação da realidade; investigação, inquirição, investigação e estudo minudentes e sistemáticos, com o fim de descobrir ou estabelecer fatos ou princípios relativos a um campo qualquer do conhecimento". Essa formulação serve para orientar a compreensão a respeito de pesquisa e de pesquisar no plano educacional, objeto de nosso interesse e que se constituirá no mote destas reflexões, especialmente sobre a formação do professor como pesquisador.

Porém, é importante retomar aquela criança mencionada anteriormente, pronta para ingressar na escola, palavra grega que significa lugar de prazer, de alegrias. Infelizmente poucas vezes na história esse conceito foi tomado como orientador das ações escolarizadas. Ao contrário, a ideia de escola disciplinadora castrou a oportunidade de brincar, de correr e de descobrir o mundo. Ainda assim, a condição humana e novas teorias pedagógicas estabeleceram a contradição e se instituíram como pedagogias alternativas, com relativo impacto nas práticas escolares. A criança que brincava nas ruas, corria por espaços amplos e abertos, subia em árvores, tomava banho em riachos, andava de bicicleta e fazia milhões de perguntas sobre as questões da vida para a família e amigos, hoje vive em pequenos 
espaços, com pouca mobilidade e convivência parental, o que, de alguma maneira, dificulta os questionamentos que lhes são naturais.

Talvez essa condição nos leve a questionar o elo entre a pesquisa, o pesquisador e a sala de aula. Como podemos ter professores pesquisadores, inquietos frente à realidade, que propiciem experiências significativas para seus alunos?

É fundamental que os docentes assumam os princípios da pesquisa para ensinar, entendendo que a aula é um importante laboratório. Não se trata de banalizar a pesquisa científica mas, de compreender que seus princípios devem acompanhar a formação, no sentido que Paulo Freire instiga. Propõe o autor que é fundamental pensar que a curiosidade que está associada ao senso comum, é a mesma curiosidade que, criticizando-se metodologicamente e respeitando-se o rigor científico, torna-se a curiosidade epistemológica. Curiosidade como uma inquietação indagadora, como uma pergunta às vezes não verbalizada a qual busca na realidade concreta as respostas.

Porque os professores em geral se afastaram da pesquisa? São possíveis múltiplas respostas a essa indagação. Antônio Nóvoa, estudioso da profissão docente em Portugal, que discute as implicações dos cursos de formação de professores como o lugar de produção docente, ressalta que é na formação inicial que o professor se assume como produtor da sua profissão. E que essa condição implica fortemente a Universidade, locus principal dessa formação.

Se os caminhos são múltiplos, a teoria e prática podem ser o nó górdio dessa equação. Como erradicá-la ou pelo menos minimizá-la? Há, atualmente, uma significativa bibliografia a respeito passando por resultados de pesquisa publicados. Mas se as pistas são importantes, a capacidade do professor de analisar a realidade da sua prática com os estudantes é que pode sugerir caminhos. As mudanças na relação teoria e prática passam por inversões dessa equação, tomando a prática, a realidade, 
como ponto de partida para a produção de conhecimento, respaldada na teoria. E é esse o caminho apontado pela pesquisa.

Entretanto, é preciso refletir que seguir nessa direção pressupõe uma mudança importante na concepção de conhecimento dos professores, que redunde numa prática inovadora. E, nessa perspectiva, é importante analisar e propor processos formativos para os docentes universitários que os estimule e instrumentalize para tal.

\section{Pesquisa e formação docente: o caminho do meio}

No aspecto cultural e social, há a necessidade de criar sistemas de formação que contemplem as condições regionais, num cenário novo, globalizado e interinstitucional, que promova a troca dos saberes. Assim, as instituições podem apresentar a possibilidade de consolidar-se como estrutura e forma, em confluência aos interesses do mercado de trabalho e das relações interpessoais. A formação, como função básica do ensino universitário, também suscita um olhar analítico às questões teórico/práticas no contexto das exigências complexas dessa sociedade.

[...] a formação é cada vez mais necessária e profunda à medida que as atividades (profissionais, sociais e, inclusive, pessoais) tornam suas exigências mais complexas. Por isso há muitas denominações dadas a esse momento histórico: sociedade da aprendizagem, sociedade da formação, formação contínua, etc. Essa presença universal do aspecto formativo e sua incorporação à dinâmica do dia-a-dia da vida das pessoas trouxeram consigo efeitos relevantes" (ZABALZA, 2004, p. 36).

No decorrer da ação formadora, configurou-se a ideia de que a educação superior encaminha para o planejamento da vida. Mas a grande valia da formação está no processo de crescimento e de aperfeiçoamento dos 
seres como pessoas. Zabalza (2004) comenta que a formação é cada vez mais necessária para o crescimento pessoal, e que o desenvolvimento se constrói pela qualidade do conteúdo e pela forma como acontece o processo de ensino.

A formação serve para qualificar o sujeito nas questões humanas, no conhecimento e nas habilidades cotidianas, enriquecendo as experiências. $\mathrm{O}$ ensino universitário depara-se com a necessidade de que o professor remeta seus discentes a uma experiência desafiadora, produtiva e conectada com a realidade. Essas experiências podem ser prazerosas e empíricas desde os primeiros semestres da graduação. Com isso algumas Universidades, instigadas por essa realidade, alteraram os currículos dos seus cursos, oportunizando aos acadêmicos essa vivência através de disciplinas que se alicerçam em uma pesquisa sócio-antropológica, que reconheça a realidade da comunidade onde estão inseridos.

Morin (2003), quando se refere à ideia de construção do conhecimento, afirma que é preciso favorecer a inter-relação entre as áreas do conhecimento, para que possa transgredir a sociedade no processo de construção e de uso desse conhecimento. Esse processo exige novas formas de ensinar, que incorpore a pesquisa, onde haja possibilidade de utilizar variadas fontes de informação/formação, compreendendo-as como processo da aprendizagem.

O imaginário social vai se construindo, tanto na academia como na profissionalização docente. Será que esse formador questiona o profissional que está formando? (BOLZAN e ISAIA, 2004). As inovações no ensino superior devem percorrer essas inquietações, passando pela imaginação, e pelo imaginário e, se possível, transformar-se em realidades positivas no processo formativo.

Para Severino (2001), a pesquisa assume uma tríplice dimensão. Por um lado está a dimensão epistemológica: a perspectiva do conhecimento. Só se conhece construindo o saber, praticando a significação dos objetos. De outro lado, tem-se a dimensão pedagógica: a perspectiva decorrente da relação com a aprendizagem. Para ele é nessa dimensão que ocorre o 
processo ensino-aprendizagem. Segundo o autor só se aprende e só se ensina pela efetiva prática da pesquisa. E a última é a dimensão social: a perspectiva da extensão.

Paulo Freire (1996), ao falar dos saberes necessários à prática educativa, chama atenção para outros aspectos e outras dimensões, igualmente importantes, sobretudo num contexto de prática reflexiva crítica. Para ele, o professor, como profissional e ser situado históricoculturalmente, produz uma prática pedagógica que pode tornar-se cada vez mais rica e significativa, se forem considerados saberes que dizem respeito a ações pedagógicas coerentes com uma opção político pedagógica democrática ou progressista. Para o autor é necessário que a prática docente tenha articulada as três dimensões: dimensão dos conhecimentos, a dimensão ético-política e a dimensão emocional-afetiva.

A "sociedade do conhecimento" demarca território por diferentes fontes e desenvolve-se por mobilizações múltiplas na sociedade. Desse modo, as leituras atualizadas possibilitam assinalar o processo de mudança nas profissões. Essas leituras, discutidas coletivamente, viabilizam o processo de troca e, consequentemente, acontece à construção coletiva de novos conhecimentos docentes que poderão ser levados para outros professores. Por essa razão ler Zabalza (2004), Morin (2002, 2003), Santos (1989, 1995, 2002), Cunha (2007, 2008), Gigante (2005), Isaia e Bolzan (2004) e outros pesquisadores é desafio producente para a pesquisa no ensino superior.

O desafio está em utilizar a pesquisa em aula como uma estratégia do processo ensino-aprendizagem onde o aluno, com instrumentalização teórico-metodológica, construa o seu conhecimento. Demo (2004) afirma que “o signo central da pesquisa é o questionamento sistemático, crítico e criativo, mais a intervenção competente na realidade, ou o diálogo crítico permanente com a realidade, em sentido teórico prático". Isso significa que é preciso buscar um olhar crítico da realidade e desenvolver nos estudantes a competência de ler a realidade e de resignificá-la. Nessa tarefa, lançar mão dos princípios da pesquisa é muito oportuno. 


\section{Algumas perspectivas teóricas}

Então vale perguntar: como fazer uso da pesquisa em sala de aula, e como podemos utilizá-la na organização do trabalho pedagógico?

Nesse caminho de resignificação procura-se compreender que o processo educativo é uma das formas de garantir as dimensões da formação integral do homem - coletivo, individual, social e histórico, que são sustentadas por princípios da solidariedade, da ética e da pluralidade cultural. À medida que os acadêmicos experienciam a pesquisa em aula desenvolvem inter-relações entre a prática profissional, os conhecimentos e os saberes cotidianos, objetivando o exercício de uma cidadania ativa, como forma de intervir na realidade onde estão inseridos. O envolvimento com a pesquisa se dá à medida em que há implicação com o objeto a ser pesquisado, ou seja, somente pesquisamos o que nos interpela e o ato de pesquisar refere-se à busca de respostas para essas inquietações.

Para Morin (2002), a educação escolarizada visa à formação integral do homem, propiciando o seu crescimento por inteiro e deve favorecer a aptidão natural da mente e estimular o uso da inteligência geral, que requer o exercício da curiosidade desde a infância. Para que isso ocorra é preciso provocar a dúvida e a incerteza e incentivar a busca de respostas para os problemas instigados pelo professor em aula, envolvendo uma concepção de ensino com pesquisa.

Santos (1995) chamou atenção para que, no paradigma de ciência emergente, o conhecimento é processo, portanto, não é absoluto, nem acabado. O desafio é criar alternativas e é nesse sentido que as aprendizagens devem caminhar. Aprender é aprender a criar e a pesquisa faz a aprendizagem ser criativa, porque é construída com esforço próprio através da elaboração pessoal e no interior de um processo coletivo, solidário e cooperativo. A pesquisa aparece como um instrumental de ensino e, como atividade inerente ao ser humano, é acessível a todos e a qualquer nível de 
escolaridade, como ponto de partida e de chegada da apreensão da realidade, dialogando com os saberes do trabalho e da cultura como forma de contextualizar o conhecimento escolar.

Fazenda (1995) enfatiza que "aprender a pesquisar, fazendo pesquisa, é próprio de uma educação interdisciplinar, que deveria iniciar na educação infantil, desde a pré-escola." Portanto, os processos de ensino devem se identificar com ações ou processos de trabalho do sujeito que aprende, pela proposição de desafios, problemas ou projetos, desencadeando, por parte dos alunos, ações resolutivas, incluídas as de pesquisa e estudo de situações, a elaboração de projetos de pesquisa, de intervenção, entre outros.

Portanto, a pesquisa na sala de aula pode estabelecer o diálogo entre as diversas áreas do saber e a postura crítica e criativa. O resultado desse diálogo volta para a realidade concreta, através de ações de intervenção crítica na vida da comunidade pesquisada. Porém, para que isso ocorra, é necessária a formação do professor-pesquisador, favorecendo o domínio da metodologia científica como instrumental do ensino.

Também Market (2000) ressalta que será importante a geração de competências, de estabelecer relações entre os sentimentos concretos e contextos sociais para poder aprofundar orientações políticas na consciência do homem. Os professores que utilizam a pesquisa em sala de aula cultivam uma rede de recursos que envolvem a comunidade nos processos de ensino, estabelecendo relações com a mesma, pois procuram fazer da comunidade um espaço de estudo para a realização de projetos. Ao propiciarmos a pesquisa em aula estaremos incentivando uma dimensão inovadora do processo ensino-aprendizagem na qual o aluno é sujeito do processo educativo quando participa da experiência, desde a concepção até a análise dos resultados. Quebra-se a estrutura vertical do poder, responsabilizando o coletivo pelo processo de ensino e aprendizagem pelas propostas formuladas. 


\section{A Mostra de Pesquisa e Extensão na Sala de Aula como estimuladora de práticas inovadoras}

Para a realização do estudo aqui descrito, tomamos as experiências apresentadas na Mostra de Pesquisa e Extensão na Sala de Aula por considerar que revelam uma preocupação institucional com a qualidade do ensino e fornecem um especial material de análise para que se compreenda o estágio de desenvolvimento da proposta inovadora na aula universitária. O intuito é compreender este tema a partir da experiência e trajetória dos professores e seus estudantes.

Reconhecendo a necessidade da indissociabilidade entre docência e pesquisa, o Projeto busca potencializar os processos de aprendizagem, proporcionando a divulgação de experiências, estimulando a autoria e a autonomia dos autores por intermédio dos estímulos às práticas inovadoras. Trata-se de uma iniciativa que quer valorizar o protagonismo da comunidade acadêmica que se propõem, instigados pela curiosidade, a desbravar as barreiras das práticas usuais de ensinar e aprender.

Ao realizarmos um levantamento das Mostras de Pesquisa em Sala de Aula a partir de 2010 (apenas com o número de alunos) e a partir de 2012 (com número de trabalhos) até 2017, foi possível contabilizar o número de trabalhos, professores e alunos que participaram do evento. Os gráficos que seguem favorecem a compreensão desse cenário em cada uma das edições. A análise nos possibilitou também visualizar o panorama amplo desse processo. 
Gráfico 1: Número de trabalhos realizados na Mostra de Pesquisa em Sala de Aula:

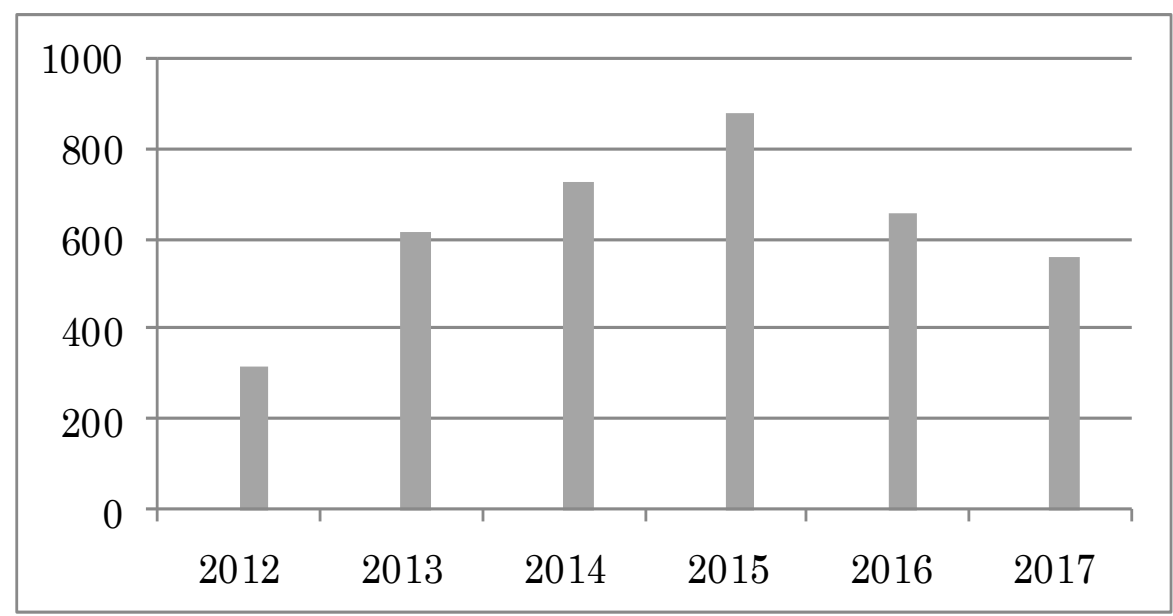

Fonte: autoras (2019).

Gráfico 2: Número de alunos por edição:

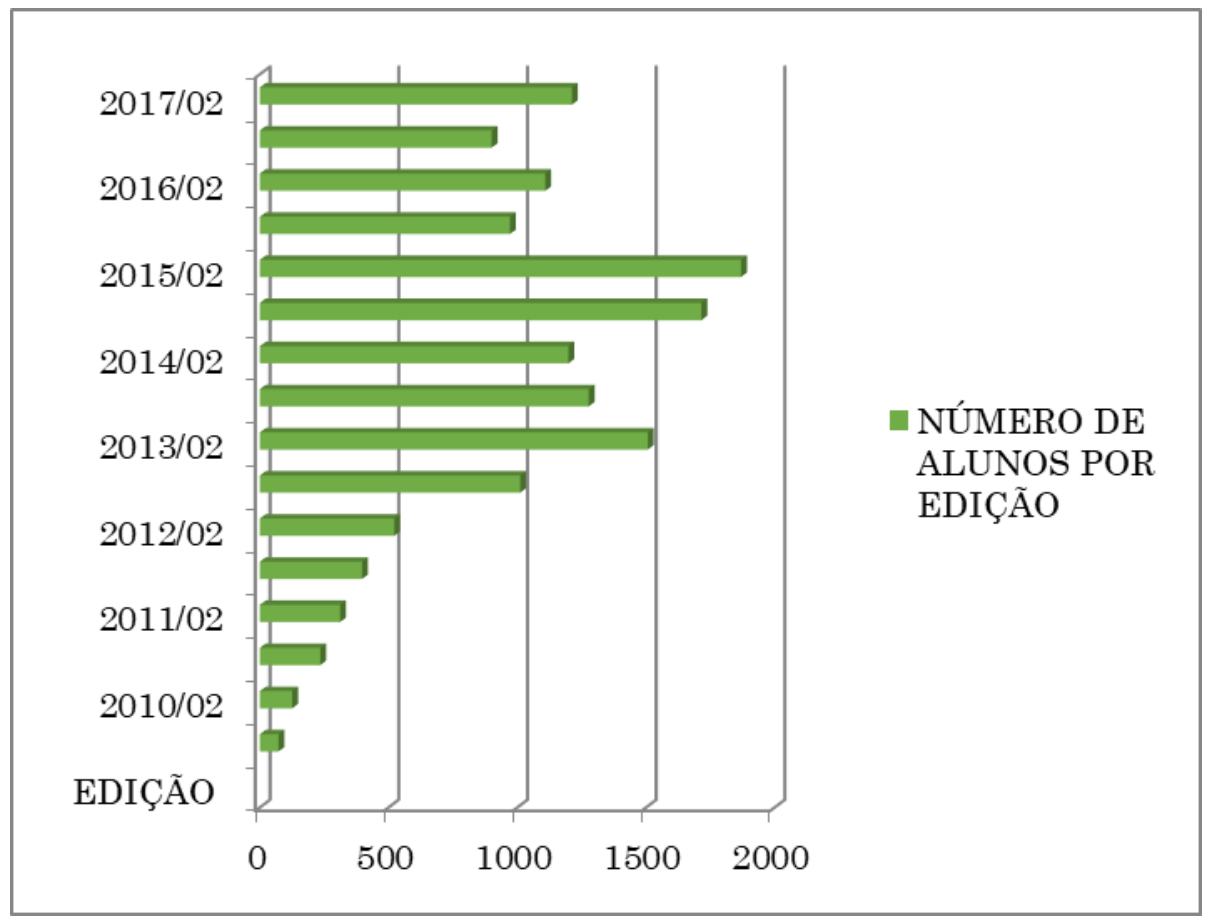

Fonte: autoras (2019).

Conforme já explicitado, buscamos localizar alguns dos profissionais que se enquadravam na categoria de docentes que realizam pesquisa de forma sistemática, pertencentes a áreas acadêmicas distintas e com reconhecida competência como professores. 
Realizamos entrevistas semi estruturadas (presenciais) e roteiros (online) com quinze professores de diferentes formações e áreas de atuação em uma instituição de ensino superior privada. A partir disso, conseguimos identificar o posicionamento de cada docente a cerca deste projeto, bem como suas perspectivas e considerações para com o aprimoramento do mesmo.

\section{Os resultados em questão}

Fundamentado a partir do embasamento teórico, troca de experiências, análise de dados e entrevistas semi estruturadas, conseguimos constatar alguns fatores para a eficácia das Mostras dentro da Universidade. As ações fundamentais dos professores influenciam em iniciativas que agregam na construção educacional dos alunos. Quando questionados sobre a fundamental importância da pesquisa relacionada à postura de ser um bom professor, os entrevistados assim se posicionaram:

"A premissa é verdadeira, afinal, é na pesquisa que a teoria pode ser colocada em prática, então qualifica mesmo o ensino. Mas discordo que bons pesquisadores são bons professores, nem todos são, e creio que não devem ser todos mesmo, pois a pesquisa científica também precisa de profissionais que sejam muito bons em outras áreas além da docência. E da mesma forma, um bom professor sabe usar a ferramenta de pesquisa para qualificar suas aulas."

"Creio ser uma premissa extremamente válida e capaz de transformar a prática docente. Certamente bons pesquisadores são bons professores, uma vez que uma característica essencial na pesquisa é o cunho investigativo e curioso. Um professor que gosta de pesquisar, provavelmente gosta de investigar mais e de incentivar seus alunos a investigar também. Uma boa prática em pesquisa é capaz de fortalecer práticas de atuação profissional ao mesmo tempo em que fortalecem as práticas de ensino."

Apesar de miradas distintas entre os professores-pesquisadores, ambos os posicionamentos afirmam a propriedade das investigações como fatores que potencializam a qualidade da pesquisa como ferramentas de ensino e que influenciam em aprendizagens com resultados significativos 
para a vida do aluno. Nossos artífices parecem nos indicar características como: qualificação do professor, compromisso social da universidade, ensino relacionado com cotidiano, aprender a ensinar no coletivo e saberes da pesquisa, condições e qualidades presentes nas suas representações de compreensão de ensino de graduação.

Os depoimentos ampliaram nossa visão obtida pelos dados numéricos, e também ressaltaram a qualidade das pesquisas apresentadas, através das participações nas Mostras, ratificando a forte influencia que a mesma sobre os métodos de ensino e as práticas pedagógicas no ensino superior. Afirmam os professores:

"A participação dos alunos em Mostras de Pesquisa em sala de aula favorece a eles descobrirem um mundo novo, pois as Mostras de Pesquisa trazem maior conhecimento sobre determinados assuntos em prática, despertando neles a curiosidade e fazendo-os cativos às pesquisas.”

"É uma grande oportunidade de fazer pesquisa ao longo do semestre, com a turma acompanhando o passo a passo metodológico, descobrindo seus caminhos e muitas vezes aprendendo muito mais do que aprenderiam com aulas sem pesquisa."

É possível considerar, também, através dos relatos dos professores de distintas áreas do conhecimento, o fundamental papel da pesquisa dentro do contexto da sala de aula, como instrumento de ensino que estimula os anseios pela incessante busca pelo conhecimento.

"Participo de todas as edições das Mostras de Pesquisa nos campi em que atuo (Gravataí e Guaíba), e vejo uma transformação dos alunos quando passam pela experiência. Já vi inúmeras vezes temas de TCC surgirem nas pesquisas de sala de aula, além de acompanhar alunos que após participarem perceberam que o caminho da pesquisa era acessível também para eles, vindo a fazer pós-graduações latu e strictu sensu."

O estudo favoreceu a compreensão de que há uma nova proposta metodológica em andamento que qualifica o trabalho em aula, permitindo uma influência não só nos discentes, mas também nos docentes. Eles se 
atualizam acerca de tendências educacionais, para promover uma educação voltada ao desenvolvimento da autonomia dos alunos.

Os resultados demonstram certa oscilação de números de Projetos na Mostra Científica, em diversificadas áreas do conhecimento, que cresce na medida em que os trabalhos organizados sejam bem gestados e que os alunos conseguem realizar troca de experiência e conteúdos no decorrer dos projetos e intervenções acadêmicas.

Certamente as políticas institucionais têm relevância na possibilidade da experiência, quer pelo incentivo como também pelas condições de trabalho e apoio para a inovação.

A semente foi lançada e a resposta foi positiva. É preciso regá-la com a esperança provendo as condições para sua realização.

\section{Considerações finais}

A partir das analises realizadas nesse período, conseguimos visualizar a potencia que a pesquisa configura no processo de ensino-aprendizagem. Através da interação que tivemos com professores e alunos no processo de construção do estudo, verificamos a clareza que os mesmos possuem sobre a influência que as Mostras de Pesquisa em Sala de Aula possuem e apresentam através de suas dimensões metodológicas integralmente construtivas.

É possível analisar também o quanto a Universidade ainda pode se desenvolver no decorrer das edições, aprimorando os métodos de intervenção para que as problemáticas envolvidas sejam sanadas. Quanto a essas adversidades, o grupo que compõe a organização das Mostras, se mostrou posicionado e comprometido em aperfeiçoar os processos envolvidos em questão. Contam, entretanto, com o apoio institucional para manter a experiência. 
Quanto à eficácia do programa em sala de aula, não somente a composição de discentes, mas também do corpo docente, mostraram-se satisfeitos em participar deste Projeto. Acreditam que a pesquisa é um instrumental de ensino que aperfeiçoa as técnicas construtivas do conhecimento, abrangendo níveis de habilidades intelectuais, sociais, operacionais, dentre outros benefícios que foi demonstrado anteriormente nesta pesquisa.

Dada às constatações possibilitadas por este estudo, é de suma relevância o projeto e sua vinculação com a qualidade da Universidade, estimulando os alunos de graduação a se aproximarem dos instrumentais da pesquisa. Através de uma prática pedagógica emancipatória se consolida as teorias investigativas durante o período da graduação. Essa iniciativa em níveis acadêmicos no ensino superior beneficia uma prática educativa que visa à qualificação da formação dos estudantes.

Demo (1997) afirma que "educar pela pesquisa é um princípio educativo e científico" que aprimora os meios de aprendizagem. Por intermédio da transformação da aula em campos de pesquisa, a experiência auxilia não só na construção do ser autônomo, mas na construção social que permeia a busca do saber, qualificado a partir de intervenções que os docentes realizam com vistas à troca de experiência nas salas de aula.

\section{Referências}

BOAVENTURA, E. M. Metodologia da pesquisa. São Paulo: Atlas, 2004.

BOLZAN e ISAIA. Revista Educação. V.29.p.121-133. Santa Maria. Disponível: http://WWW.ufsm.br/ce/revista.

CUNHA, M. I. da. Os conceitos de espaço, lugar e território nos processos analíticos da formação dos docentes universitários. São Leopoldo, Unisinos, 2007.

CUNHA, M. I da. O campo da Pedagogia Universitária: legitimidades e desafios para a profissionalidade docente. São Leopoldo, Unisinos, 2008a. 
CUNHA, M. I. da. Formação docente e inovação: epistemologias e pedagogias em questão. In: EGGERT, E. et al. (Org.). Trajetórias e processos de ensinar e de aprender: didática e formação de professores. Porto Alegre: EDIPUCRS, 2008b, p. 465-476.

DEMO, P. Educar pela Pesquisa. Campinas, SP: Autores Associados, 1997.

FAZENDA, I. C. A. Interdisciplinariedade: história, teoria e pesquisa. $2^{\mathrm{a}}$.ed. Campinas, SP. Papirus, 1995. (Coleção Magistério:Formação e trabalho pedagógico).

FREIRE, P. Pedagogia da autonomia: saberes necessários à prática educativa. São Paulo: Paz e Terra, 1996.

MARKET, W. Novas competências no mundo do trabalho e suas contribuições para formação do trabalhador. GT09: Trabalho e Educação. 2000.

MORIN, E. Os sete saberes necessários para a educação do futuro. $6^{a}$ ed. São Paulo: Cortez, Brasília, DF. UNESCO. 2003.

A cabeça bem-feita: repensar a reforma, reformar o pensamento. Trad.:

Eloá Jacobina. 7a ed. Rio de Janeiro: Bertrand Brasil, 2002.

SANTOS, B. de S. Pela Mão de Alice: O social e o Político na Pós-modernidade. São Paulo, Cortez, 1995.

. A crítica da razão indolente: contra o desperdício da experiência. 4. ed. São Paulo: Cortez, 2002.

. Introdução a uma ciência pós-moderna. Rio de Janeiro: Graal, 1989.

SEVERINO, A; J. Docência universitária: a pesquisa como princípio pedagógico. 2001.Disponível em Acesso em 17 de dezembro de 2012.

ZABALZA, M. A. O ensino universitário: seu cenário e seus protagonistas/ Porto Alegre, RS: ARTMED, 2004. 